\title{
Characterization of $\mathrm{Cr}-\mathrm{Ni}$ multilayers electroplated from a chromium(III)-nickel(II) bath using pulse current
}

\author{
Ching An Huang, ${ }^{\mathrm{a}, *}$ Chao Yu Chen, ${ }^{\mathrm{a}}$ Chun Ching $\mathrm{Hsu}^{\mathrm{a}}$ and Chao Sung Lin ${ }^{\mathrm{b}}$ \\ ${ }^{a}$ Department of Mechanical Engineering, Chang Gung University, Taoyuan, Taiwan \\ ${ }^{\mathrm{b}}$ Department of Materials Science and Engineering, National Taiwan University, Taipei, Taiwan
}

Received 8 December 2006; revised 29 January 2007; accepted 2 February 2007

Available online 16 April 2007

$\mathrm{Cr}-\mathrm{Ni}$ multilayers with thickness modulation of several tens of nanometers were prepared by pulse-current electroplating from a $\mathrm{Cr}(\mathrm{III})-\mathrm{Ni}(\mathrm{II})$ bath at $30^{\circ} \mathrm{C}$. The $\mathrm{Cr}-\mathrm{Ni}$ multilayers were composed of alternate amorphous Cr-rich and nanocrystalline Ni-rich layers. This amorphous Cr-rich layer could be attributed to a reduction in the complex-formed $\mathrm{Cr}$ ion, which leads to the presence of $\mathrm{C}$, a glass-forming element, in the Cr-rich deposit during electrodeposition. Twins were found in the nanosized Ni-rich layer, in which stacking faults were frequently observed.

(C) 2007 Acta Materialia Inc. Published by Elsevier Ltd. All rights reserved.

Keywords: Cr-Ni multilayers; Electroplating; Microstructure

Multilayer structures have attracted attention in the field of engineering because such structures have a considerable number of practical applications and fundamentally interesting properties [1]. Different types of multilayers have been developed by physical vapor deposition (PVD) or chemical vapor deposition (CVD). Recently, electroplating has been employed for fabricating multilayers, because of its low cost and convenience in operation. For example, multilayers of $\mathrm{Cu}-$ $\mathrm{Ni}, \mathrm{Ni}-\mathrm{W}-\mathrm{P}, \mathrm{Co}-\mathrm{Cu} / \mathrm{Cu}$ and $\mathrm{Co}-\mathrm{Ni}(\mathrm{Cu}) / \mathrm{Cu}$ have been successfully fabricated by means of electroplating [2-5].

Hard $\mathrm{Cr}$ electrodeposits have been used extensively to protect the base metal from corrosion and wear. These deposits are generally electroplated from a hexavalent $\mathrm{Cr}$ bath, which is known to be highly toxic. Several trivalent $\mathrm{Cr}$ solutions have thus been developed for the electrodeposition of Cr-based alloys [6,7]. However, most trivalent $\mathrm{Cr}$ baths exhibit poor stability and lack of repeatability during electroplating [8].

In this study, $\mathrm{Cr}-\mathrm{Ni}$ deposits composed of alternative $\mathrm{Cr}$-rich and Ni-rich layers were electroplated from a bath containing trivalent $\mathrm{Cr}$ and divalent $\mathrm{Ni}$ ions using a pulse current. The thickness of each layer was controlled to be tens or a few nanometers by varying the

\footnotetext{
* Corresponding author. Tel.: +886 32118800 ; fax: +886 32118050 ; e-mail: gfehu@mail.cgu.edu.tw
}

duration of each pulse cycle, as characterized by highresolution transmission electron microscopy (HRTEM).

$\mathrm{Cr}-\mathrm{Ni}$ alloy electroplating was conducted in the bath containing $0.8 \mathrm{M} \mathrm{CrCl}_{3} \cdot 6 \mathrm{H}_{2} \mathrm{O}$ and $0.4 \mathrm{M} \mathrm{NiCl}_{2} \cdot 6 \mathrm{H}_{2} \mathrm{O}$, and urea as a complex agent. A small amount of conductive and buffer salts were added to give a $\mathrm{pH}$ of 1.1 [9], and the bath temperature was maintained at $30 \pm 1^{\circ} \mathrm{C}$ by a thermosetter. Electroplating was performed in a typical electrochemical three-electrode cell, together with a potentiostat/galvanostat (EG\&G Model 263A) to control a rotating cylinder electrode (RCE, EG\&G Model 636) made of brass with a diameter of $9.5 \mathrm{~mm}$ and length of $6.7 \mathrm{~mm}$. A platinized Ti mesh and an $\mathrm{Ag} / \mathrm{AgCl}$ electrode in a saturated solution of $\mathrm{KCl}$ were used as the counter and reference electrodes, respectively. Before electroplating, the surface of the RCE was mechanically ground to 2400 grit emery paper, ultrasonically cleaned in acetone, rinsed with deionized water and then dried with a cold air blaster.

The current density for electroplating was varied from 5 to $45 \mathrm{~A} \mathrm{dm}^{-2}$, while the rotation speed of RCE was kept at $300 \mathrm{rpm}$ for each run of electroplating. After electroplating, the RCE was ultrasonically cleaned in acetone, dried with a hot air blaster and then prepared for microstructure characterization. The surface morphology of the deposit was observed using a scanning electron microscope (SEM), and the average composition of the deposit was measured using X-ray energydispersive spectroscopy (EDS) in the SEM. The detailed 
microstructure of the deposit was studied by HRTEM (HRTEM, Philips Tecnai F30) on the cross-sectional specimen, which was prepared as follows: two pieces of $\mathrm{Cr}-\mathrm{Ni}$ multilayers were sectioned with a diamond saw to produce samples $1 \mathrm{~mm}$ thick, $1.5 \mathrm{~mm}$ long and $1 \mathrm{~mm}$ wide, glued face to face with M-Bond 610 epoxy and mounted vertically in a copper ring of $3 \mathrm{~mm}$ diameter with G1 epoxy (Gatan Company, USA). The specimen was then mechanically ground to a thickness of $\sim 100 \mu \mathrm{m}$, and two sides of the specimen were further mechanically ground to a dimple shape using Dimpler (VCR, D500i, USA) until the thickness of the specimen was approximately $10 \mu \mathrm{m}$ at the center. Finally, a low angle $\left(\sim 8^{\circ}\right) \mathrm{Ar}^{+}$-ion milling machine (VCR, XLA 2000 , USA) operated at $5 \mathrm{kV}$ was used to thin the specimen until a tiny hole was produced in the glued $\mathrm{Cr}-\mathrm{Ni}$ multilayer. Around the hole, the deposit was thin enough for observation and electron diffraction analysis under a transmission electron microscope. Details of the preparation procedure were reported elsewhere [10].

Under visual observation on the surface of the deposit, bright $\mathrm{Cr}-\mathrm{Ni}$ deposits were made at a current density ranging from 10 to $40 \mathrm{~A} \mathrm{dm}^{-2}$. Electrodeposition rates were too slow at current densities below $10 \mathrm{~A} \mathrm{dm}^{-2}$, whereas friable matt $\mathrm{Cr}-\mathrm{Ni}$ deposits were made at current densities exceeding $50 \mathrm{~A} \mathrm{dm}^{-2}$.

Figure 1 shows the composition of the $\mathrm{Cr}-\mathrm{Ni}$ deposit as a function of the current density. The $\mathrm{Cr}$ content in the deposit increased markedly with increasing current density from 10 to $30 \mathrm{~A} \mathrm{dm}^{-2}$, followed by a constant of $\sim 85 \mathrm{wt} . \%$ as the current density was increased from 30 to $40 \mathrm{~A} \mathrm{dm}^{-2}$. As shown in Figures 1 and 2, a crack-free Ni-rich deposit with $\sim 99$ wt. $\% \mathrm{Ni}$ was plated at $10 \mathrm{~A} \mathrm{dm}^{-2}$, while a $\mathrm{Cr}$-rich deposit of $\sim 85 \mathrm{wt} . \% \mathrm{Cr}$ with networks of cracks was produced at $30 \mathrm{~A} \mathrm{dm}^{-2}$. It is generally believed [11] that surface cracking in a $\mathrm{Cr}$ deposit could reduce its residual stress developed during the electroplating of metallic $\mathrm{Cr}$. The same trend can be observed on the $\mathrm{Cr}$-rich deposit electroplated at relatively high current densities, i.e. exceeding $30 \mathrm{~A} \mathrm{dm}^{-2}$. In contrast, a uniform and crack-free $\mathrm{Ni}$ rich deposit was electrodeposited at $10 \mathrm{~A} \mathrm{dm}^{-2}$. Apparently, the $\mathrm{Cr}-\mathrm{Ni}$ deposits electroplated at 10 and $30 \mathrm{~A} \mathrm{dm}^{-2}$, respectively, exhibited quite different surface morphologies and compositions, suggesting that different structures can be achieved by plating at these current densities. To obtain $\mathrm{Cr}-\mathrm{Ni}$ multilayers with different

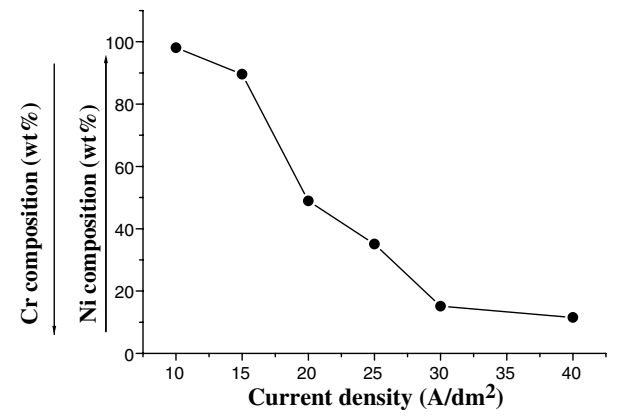

Figure 1. Effect of current density on the composition of $\mathrm{Cr}-\mathrm{Ni}$ deposits electroplated from the $\mathrm{Cr}(\mathrm{III})$ and $\mathrm{Ni}(\mathrm{II})$ bath using $\mathrm{DC}$ current.
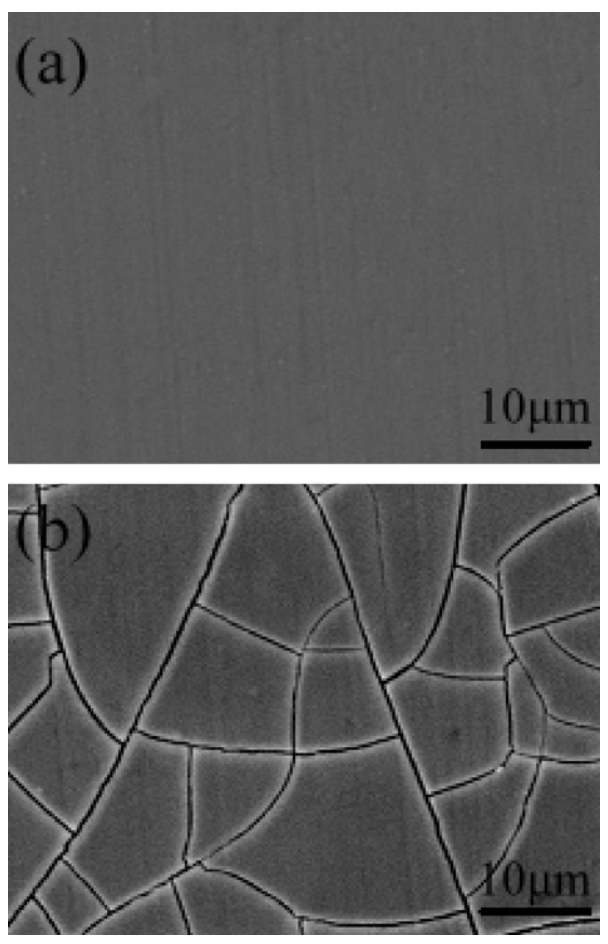

Figure 2. Morphologies of the various $\mathrm{Cr}-\mathrm{Ni}$ deposits: (a) crack-free Ni-rich deposit plated at $10 \mathrm{~A} \mathrm{dm}^{-2}$ and (b) Cr-rich deposit with a network of cracks (electroplated at $30 \mathrm{~A} \mathrm{dm}^{-2}$ ).

thickness modulations, pulse plating was conducted for 1 min with 2 and $6 \mathrm{~s}$ pulse cycles, respectively. Furthermore, in each pulse cycle, the current density was performed at 10 or $30 \mathrm{~A} \mathrm{dm}^{-2}$ for the same duration period. Thus, it can be expected that $\mathrm{Cr}-\mathrm{Ni}$ multilayers with two different thickness modulations can be achieved.

Figure $3 \mathrm{a}$ and $\mathrm{b}$ shows the potential response during pulse plating with 2 and 6 s pulse cycles, respectively. It can be clearly seen that the potential responded synchronically with the applied current density, i.e. $-3.2 \mathrm{~V}$ (vs. $\mathrm{Ag} / \mathrm{AgCl}\left(\right.$ sat.)) at $30 \mathrm{~A} \mathrm{dm}^{-2}$ and $-1.6 \mathrm{~V}$ (vs. $\mathrm{Ag} /$ $\mathrm{AgCl}\left(\right.$ sat.)) at $10 \mathrm{~A} \mathrm{dm}^{-2}$, respectively. These values were also in good agreement with the cathodic potentials with DC plating, but included substantial uncompensated ohmic potential losses, as the reference electrode was $\sim 15 \mathrm{~mm}$ away from the RCE. It is known [12] that electroplating in a single bath with the presence of two different chemical components in the multilayer is what is desired. Hence, when the cathode potential is set to a value appropriate for the reduction of the less noble component, both metals will be deposited, resulting in an alloy layer. From the results of Figure 1, Cr- and $\mathrm{Ni}$-rich deposits were achieved individually by regulating the current density: lower current densities or less negative reduction potentials for Ni-rich deposits, and higher plating current densities or lower reduction potentials for $\mathrm{Cr}$-rich deposits. Hence, a multilayer structure with a modulation of $\mathrm{Ni}$ - and $\mathrm{Cr}$-rich deposits can be expected to be deposited by means of pulse plating with the current densities specified in Figure 1.

Figures $4 \mathrm{a}$ and $\mathrm{b}$ show cross-sectional TEM micrographs of multilayer deposits electroplated with pulse 
a

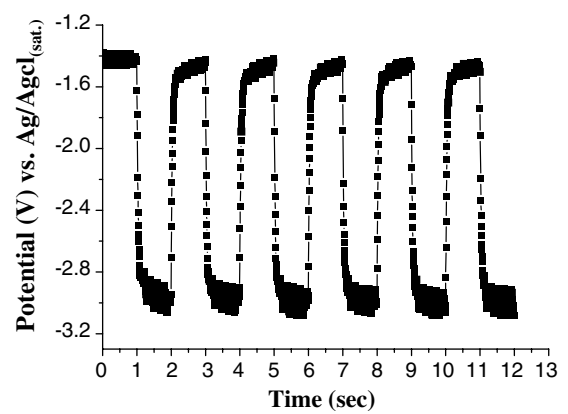

b

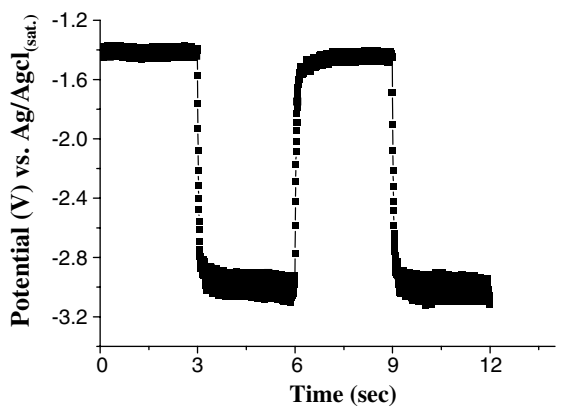

Figure 3. Potential response during pulse-current electroplating for pulse cycles of (a) $2 \mathrm{~s}$ and (b) $6 \mathrm{~s}$.
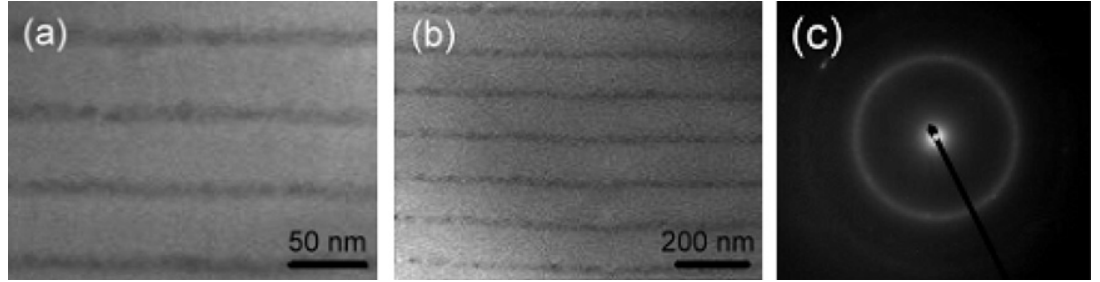

Figure 4. Cross-sectional TEM micrographs of Cr-Ni multilayers electroplated with pulse cycles of (a) $2 \mathrm{~s}$, (b) $6 \mathrm{~s}$ and (c) selected area electron diffraction pattern of the multilayer shown in (b).

cycles of 2 and $6 \mathrm{~s}$, respectively. Apparently the $\mathrm{Cr}-\mathrm{Ni}$ multilayers with different thickness modulations were obtained. Electroplating with a pulse cycle of $6 \mathrm{~s}$, a $\mathrm{Cr}-\mathrm{Ni}$ multilayer with a thickness modulation of $150 \mathrm{~nm} \mathrm{Cr}$ - and $25 \mathrm{~nm}$ Ni-rich layers was achieved, while $60 \mathrm{~nm} \mathrm{Cr}$ - and $10 \mathrm{~nm}$ Ni-rich layers were observed with a pulse cycle of $2 \mathrm{~s}$. The thickness ratio of $\mathrm{Cr}$-rich to Ni-rich layers was calculated to be around six regardless of the period of each pulse cycle. According to Faraday's law, the thickness of the deposit layer is proportional to the charge imposed during the plating period. Because of the same duration period, the charge imposed at $30 \mathrm{~A} \mathrm{dm}^{-2}$ is three times that at $10 \mathrm{~A} \mathrm{dm}^{-2}$. This charge ratio was smaller than the thickness ratio, signifying that the Cr-rich layer was deposited at a higher cathodic current efficiency than the Ni-rich layer. Furthermore, the thickness of the $\mathrm{Cr}$ - and Ni-rich layers can be adjusted by varying the current density and its duration for each pulse cycle.

Figure $4 \mathrm{c}$ is the selected area electron diffraction (SAED) patterns of the multilayer plated at a $6 \mathrm{~s}$ pulse cycle. The SAED pattern was not significantly different from the one plated at a $2 \mathrm{~s}$ pulse cycle. That is, both multilayers contained diffuse halos and continuous rings in their SAED patterns. This implies that the multilayers are constructed with alternate amorphous and crystalline layers. Figure 5a presents an HRTEM micrograph of the multilayer plated with a $6 \mathrm{~s}$ pulse cycle showing that the Ni-rich layer consisted of fine equiaxed grains with an average size of $\sim 7 \mathrm{~nm}$; while the Cr-rich layer displayed an amorphous structure. Moreover, wavy interface was observed between $\mathrm{Cr}$ - and Ni-rich layers. Figures $5 \mathrm{~b}$ and $\mathrm{c}$ show the EDS spectra taken from the Ni- and Cr-rich layers, respectively, using an electron probe of $4 \mathrm{~nm}$ diameter. As expected, Ni- and $\mathrm{Cr}-$ rich layers were obtained when plated at 10 and
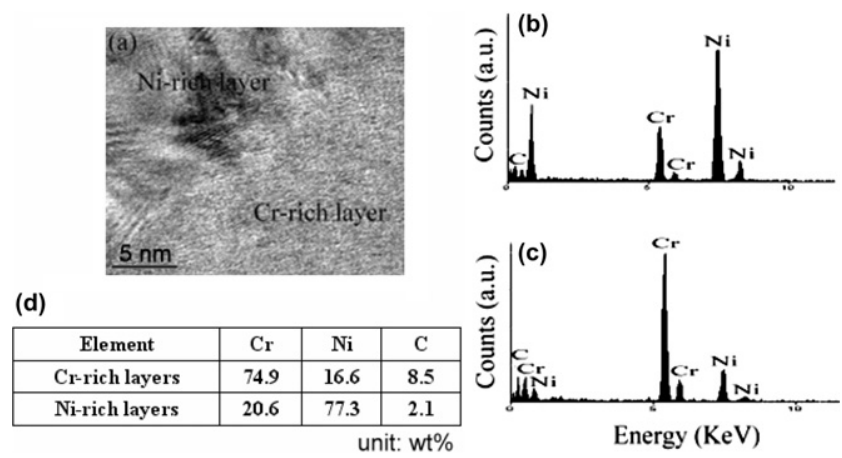

Figure 5. (a) HRTEM micrograph of $\mathrm{Cr}-\mathrm{Ni}$ multilayer electroplated with $6 \mathrm{~s}$ pulse cycle and the EDS spectra from (b) Ni-rich layer and (c) $\mathrm{Cr}$-rich layer. The quantitative chemical compositions in the $\mathrm{Cr}$-rich and Ni-rich layers are presented in (d).

$30 \mathrm{~A} \mathrm{dm}^{-2}$, respectively. The Ni-rich layer deposited via pulse plating contained a significantly higher $\mathrm{Cr}$ content than that plated using a DC current of $10 \mathrm{~A} \mathrm{dm}^{-2}$, at which a deposit with $\sim 99$ wt.\% Ni was made (see Fig. 1).

It is well known that amorphous metal, or metallic glass, is very difficult to fabricate using conventional manufacturing processes. Several researchers have found that amorphous $\mathrm{Cr}$ deposits can be obtained from a trivalent $\mathrm{Cr}$ bath containing complex agents such as urea and formic acid $[11,13]$. In contrast, the $\mathrm{Cr}$ deposit plated from a hexavalent $\mathrm{Cr}$ sulfate bath shows a crystalline structure [14]. Nevertheless, Hoshino et al. [15] have reported that an amorphous Cr deposit can be plated by adding small amounts of formic acid to a hexavalent $\mathrm{Cr}$ bath. Therefore, complex agents can play an important role in the electrocrystallization of a $\mathrm{Cr}$ deposit. In the present study, urea was used as a complex 


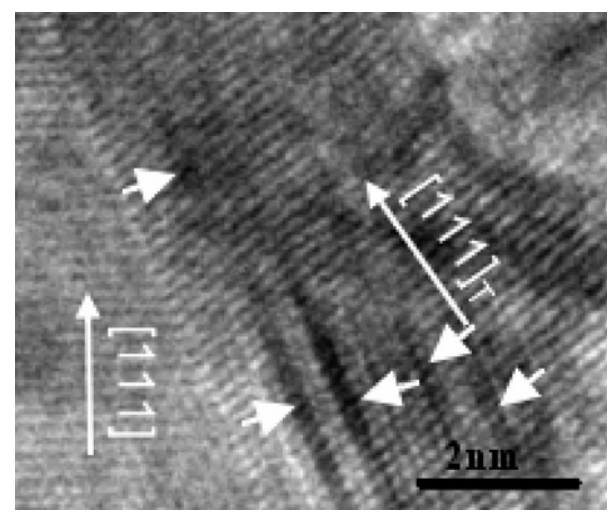

Figure 6. HRTEM micrograph of a nanosized Ni-rich grain showing the stacking fault structure in deformation twin.

agent; meanwhile, it provides carbon source to the deposit [16]. This can be clearly seen from the EDS spectrum shown in Figure 5c, in which a $\mathrm{C} \mathrm{K}_{\alpha}$ signal was detected in the Cr-rich layer. Song and Chin [17] have proposed that complex-formed $\mathrm{Cr}$ in the form of $\mathrm{Cr}$ [complex former $]^{+}$was present adjacent to the growing deposit during electroplating. The reduction of complex-formed $\mathrm{Cr}$ resulted in significant amounts of $\mathrm{C}$ in the $\mathrm{Cr}$ deposit (see Fig. 5d). Since C, being metalloid, is known to be a glass-forming element, the growing deposit might hinder the crystallization of the $\mathrm{Cr}$ deposit.

Contrary to the amorphous Cr-rich layer, the Ni-rich layer was composed of nanosized grains, as shown in Figure 6. This indicates that electrocrystallization of the Ni-rich layer was hardly affected by the complex former, and Ni nuclei formed easily in the bath containing $\mathrm{Cr}(\mathrm{III})$ and Ni(II) ions. Figure 6 also shows that Ni-rich grains contained a high density of twins. For example, the interfacial angle between [111] in the grain and $\left[\begin{array}{lll}1 & 1 & 1\end{array}\right]_{\mathrm{T}}$ in the twin was measured to be $\sim 40^{\circ}$, which corresponds well to a typical twinned face-centered cubic crystal such as Ni lattice diffracted with a zone axis of [1 110$]$ [18]. It is worth mentioning that stacking faults were frequently observed in Ni-rich grains, as marked by the arrow in Figure 6. The correlation between stacking fault structure in deformation twins has been uncovered in the literature [19]. However, this present study further confirms that a stacking fault can form in the twinned region of the Ni-rich layer during electrocrystallization.

The authors wish to thank the National Science Council (NSC) of Republic of China for the support of this work under Contract No. NSC 95-2221-E-182022.

[1] A. Marlot, P. Kern, D. Landolt, Electrochim. Acta 48 (2002) 29.

[2] Ch. Bonhote, D. Landolt, Electrochim. Acta 42 (1997) 2407.

[3] C.N. Panagopoulos, V.D. Papachristos, L.W. Christoffersen, Thin Solid Films 366 (2000) 155.

[4] J.J. Kelly, P. Bradley, D. Landolt, J. Electrochem. Soc. 174 (2000) 2975.

[5] S.M.S.I. Dulal, E.A. Charles, S. Roy, Electrochim. Acta 49 (2004) 2041.

[6] Tz. Boiadjieva, D. Kovacheva, K. Petrov, S. Hardcastle, A. Sklyarov, M. Monev, J. Appl. Electrochem. 34 (2004) 315.

[7] J.-C. Kang, S.B. Lalvani, J. Appl. Electrochem. 22 (1992) 787.

[8] Baosong Li, An Lin, Fuxing Gan, Surf. Coat. Technol. 201 (2006) 2578.

[9] Chao Yu Chen, Chun Ching Hsu, Ui Waio Liu, Ching An Huang, ECS Trans. 2 (2006) 413.

[10] Hans-Joachim Klaar, Ching-An Huang, Prakt. Metallogr. 31 (1994) 290.

[11] S.C. Kwon, M. Kim, S.U. Park, D.Y. Kim, D. Kim, K.S. Nam, Y. Choi, Surf. Coat. Technol. 183 (2004) 151.

[12] D. Landolt, A. Marlot, Surf. Coat. Technol. 8 (2003) 169.

[13] A. Watson, Y.J. Su, M.R. El-Sharif, C.U. Chisholm, Trans. Inst. Met. Finish. 71 (1993) 15.

[14] Cloyd A. Snavely, Charles L. Faust, J. Electrochem. Soc. 97 (1950) 99.

[15] S. Hoshino, H.A. Laitinen, G.B. Hoflund, J. Electrochem. Soc. 133 (1986) 681.

[16] S.K. Ibrahim, D.T. Gawne, A. Watson, Trans. Inst. Met. Finish. 76 (1998) 156.

[17] Y.B. Song, D.-T. Chin, Electrochim. Acta 48 (2002) 349.

[18] J.W. Edington, Monographs in practical electron microscopy in materials scienceElectron Diffraction in the Electron Microscope, vol. 2, Philips Technical Library, 1975, pp. 44 48.

[19] J.A. Venables, in: Proceedings of Fifth International Conference on Electron Microscopy 1, 1962, J8. 